The Ss were subjected to daily handling from 3 to 28 days of age. This consisted of removing $\mathrm{S}$ from the home cage, stroking its back for approximately $1 \mathrm{~min}$, and then depositing $S$ on the sawdust floor of a fresh cage. After Ss in each litter had been handled in the same manner, they were returned to the home cage one by one. At 28 days of age, Ss were weaned and thereafter received treatment identical to that given $S s$ in Experiment 1.

The Ss were tested for a single 35-min session at 80 days of age according to the procedure described in Experiment 1.

\section{Results}

Figure 4 compares the behavior of the handled group with the results of the first day of testing in Experiment 1, in which Ss were not exposed to the early handling procedure. Here, SC, defecation, and activity are plotted for each of the 35 min of testing. It is clear that each component of the response pattern was greatly reduced or completely abolished by early handling. Also, the tonic level of activity was much higher in the handled group $(p<.01)$, a finding that is consistent with the results of Levine et al (1967), Denenberg, Schell, Karas, \& Haltmeyer (1966), and others

\section{DISCUSSION}

Experiment 1 showed that a large increment in SC accompanies eliminatory and locomotor responses to an aversive stimulus. Experiment 2 showed that early handling greatly reduces or abolishes the SC, defecation, and freezing responses that normally would have been observed on the first day of testing. These findings provide further evidence for control of the electrodermal system of the mouse by a neural mechanism that regulates emotional defecation and agonistic locomotor responding.

The effect of early handling, which was rather striking, may be interpreted in one of two ways. The first possibility is that early handling lowers susceptibility to emotional arousal (Denenberg, 1964). :A different account, however, attributes the effect of handling to habituation to a specific stimulus situation rather than to a general lowering of emotional reactivity. The possible role of habituation would have been maximized in the present study by the similarity, due to the presence of $E$, of conditions during treatment and testing. The extent to which the effect of early handling is due to habituation, rather than to a lowering of emotional reactivity, is unclear and remains a problem for future research.

\section{REFERENCES}

DENENBERG, V. H. Critical periods, stimulus input, and emotional reactivity: A theory of infantile stimulation. Psychological Review, 1964, 71, 335-351. DENENBERG, V. H., SCHELL, S. F., KAR AS, G. G., \& HALTMEYER, G. C. Comparison of background stimulation and handling as forms of infantile stimulation. Psychological Reports, 1966. 19, 943-948.

HUNT, H. F., \& OTIS, L, Conditioned and unconditioned emotional defecation in the rat. Journal of Comparative \& Physiological Psychology, 1953, 46, 378-382.

LEVINE, S. The effects of infantile experience on adult behavior. In $A$. I Bachrach (Ed.), Experimental foundations of clinical psychology. New York: Basic Books, 1962. Pp. 139-169.

LEVINE, S., HALTMEYER, G. C., KARAS, G. G., \& DENENBERG, V. H. Physiological and behavioral effects of infantile stimulation. Physiology \& Behavior, 1967, 2, 55-59.

LINDZEY, G., WINSTON, H. D., \& MANOSEVITZ, $M$. Early experience, genotype, and temperament in Mus musculus. Journal of Comparative \& Physiological Psychology. 1963, 56. $622-629$.

ROBERTS, L. E. Central, peripheral, and artifactual determinants of skin resistance in the mouse. Journal of Comparative \& Physiological Psychology. $1967 \mathrm{a}, 64,318-328$.

ROBERTS, L. E. Changes in skin conductance and operant behavior during discriminative CER conditioning in the mouse. Paper presented at the annual meeting of the Eastern Psychological Association, Boston, April 1967b.

WOLL, $S$. V. Conditioned-suppression in the rat: Concomitant changes in skin conductance and sikin potential as measured by an improved grid technique. Unpublished Master's thesis, McMaster University, 1968.

\section{NOTE}

1. Roberts, L. E., \& Young, R. Heart rate is related to movement during classical conditioning in the rat, but skin conductance and potential are not. Submitted for publication.

\title{
The effects of a tranquilizer on the immobility reaction in chickens: Additional support for the fear hypothesis
}

GORDON G. GALLUP, JR., RICHARD F. NASH, and CHARLES W. BROWN Tulane University, New Orleans, La. 70118

In terms of number of inductions needed to elicit the immobility response, chickens given metoserpate HCL (Pacitran) were found to be significantly less susceptible to immobility than controls. The duration of resulting immobility reactions was also found to be inversely related to drug dosage levels, with controls remaining immobile over three times longer than chicks receiving an optimal dosage. The results were interpreted as lending support to the notion that fear is what underlies tonic immobility reactions in young chicks.

Recent research has provided considerable support for the idea that the tonic immobility response in chickens represents a fear reaction. The application of standard fear-induction procedures such as electric shock (Gallup, Creekmore, \& Hill, 1970) and loud noise (Gallup, Nash, Potter, \& Donegan, 1970), as well as confrontation with potential predators (Gallup \& Nash, 1970), have all been shown to reliably enhance immobility reactions in young chicks.

An alternate approach to testing the fear hypothesis would be to employ procedures designed to reduce, rather than increase, fear. It is well known, for example, that handling, familiarization, and repeated testing cause the immobility response in chickens to wane (Gilman, Marcuse, \& Moore, 1950; Ratner \& Thompson, 1960). Another possibility might be the use of tranquilizing agents as a technique for reducing fear or arousal. Although numerous attempts to look at the effect of various drugs on the immobility reaction have been made, the results are contradictory (see review by Ratner, 1967).

Part of the problem resides in the fact that there are sometimes large species differences in response to a given tranquilizing agent (e.g., Garren \& Hill, 1957). Another difficulty relates to the technique employed in administering the drug. Pilot data from our laboratory indicate that injections (IV or IM) may, by virtue of their inherent fear and/or stress-producing effects, mask the effect of the drug on immobility; e.g., chickens given isotonic saline or chlorpromazine injections have often remained immobile for over $2 \mathrm{~h}$.

Recently, a new water-soluble tranquilizer (Pacitran, CIBA) was developed specifically for use with poultry, and numerous reports (e.g., Belloff \& Hsu, 1963; Champion, Zindel, Ringer, \& Wolford, 1966) have documented its effectiveness for reducing emotionality in chickens subject to commercial handling. Moreover, the drug can be administered by simply adding it to drinking water following a specified 
period of water deprivation, and thereby obviates possible fear confounding associated with its application.

The purpose of the present study was to look at various measures of immobility under different amounts of the above-mentioned tranquilizer as another test of the fear hypothesis.

\section{SUBJECTS}

The Ss were 41 Production Red chicks (Gallus gallus) obtained from a local hatchery at 4 days of age. All animals were housed in commercial brooders providing thermostatically controlled temperature regulation. During rearing, the birds were given free access to Purina chick chow (Growena) and water, and the photoperiod in effect throughout the experiment was $14 \mathrm{~h}$ of natural and artificial light per day.

\section{APPARATUS}

The apparatus consisted of a three-sided wooden induction box, mounted on a table in a separate experimental room. Hunter Klockounter timers (Model 120A), wired to silent single-throw switches, were used to record duration of the immobility reactions. Large cardboard boxes situated outside the experimental room were used as preand posttest holding containers.

\section{PROCEDURE}

At 3 weeks of age, all birds were fitted with numbered plastic leg bands for purposes of identification. After the chicks were 4 weeks old, they were divided randomly into four groups, which resulted in 11 birds in the control group and 10 in each of the remaining three groups. It was determined that a mixture of $1.4 \mathrm{~g}$ of metoserpate HCL (Pacitran) per gallon of water would give rise to a $1-\mathrm{mg} / \mathrm{kg}$ body-weight dosage, with $10-15 \mathrm{~min}$ ad lib drinking following $3-4 \mathrm{~h}$ of water deprivation, at room temperature of $70^{\circ}-80^{\circ} \mathrm{F} .{ }^{1}$ Prior to testing, the chicks in each group were deprived of water for $230 \mathrm{~min}$ during daylight hours at $72^{\circ} \mathrm{F}$ room temperature. Following deprivation, the birds were given free access to water containing different amounts of Pacitran, which resulted in approximate dosage levels of $0,1,2$, and $4 \mathrm{mg} / \mathrm{kg}$ body weight. All birds were tested between 2 and $5 \mathrm{~h}$ after ingestion of the tranquilizer (optimum tranquilization begins after $90 \mathrm{~min}$ and lasts for about $12 \mathrm{~h}$ ).

No attempt was made to adapt or habituate birds prior to testing. Testing consisted of manually restraining a bird on its right side for $15 \mathrm{sec}$. The resulting duration of immobility was recorded to the point of self-termination, as defined by a bird getting to its feet, or until a maximum of $1,500 \mathrm{sec}$ had been

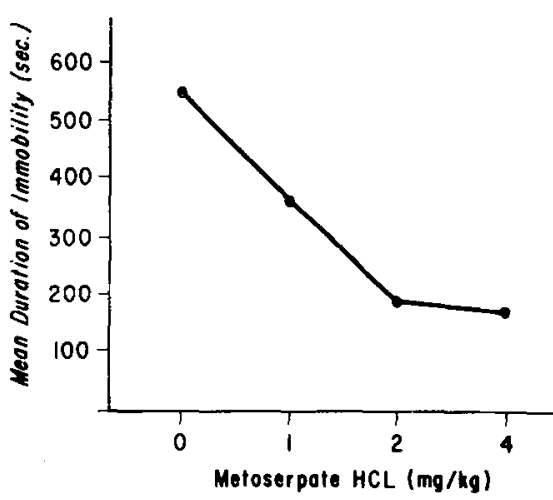

Fig. 1. Mean duration of self-paced immobility in 4-week old chickens as a function of approximate drug dosage levels.

reached. During the immobility episode the $E$ sat on a chair about $3 \mathrm{ft}$ away and avoided making direct eye contact with the $S$. If a chick did not show the immobility response after the first induction, it was given successive 15-sec inductions until immobility obtained or until five inductions had been administered, in which case a duration of zero was recorded.

RESULTS AND DISCUSSION

The effect of different levels of tranquilization on duration of the immobility response following the first induction is depicted in Fig. 1. In general, birds receiving the drug remained immobile for appreciably shorter periods of time than did controls. Chicks in the control group remained immobile 3.19 times longer than those in the 4-mg/kg group, with means of 549.3 and $171.8 \mathrm{sec}$, respectively. To normalize the data for analysis, a transformation of the form $\log _{1}(X+1)$ was performed on the raw scores, and the resulting data were analyzed via a one-way analysis of variance. The overall effect of the tranquilizer by way of reducing the immobility episode proved to be statistically significant $\quad(F=2.98$, $\mathrm{df}=3 / 37, \mathrm{p}<.05)$.

Not only did the tranquilizer reduce the duration of immobility in response to manual restraint, but it also affected susceptibility to immobility. In the control group and the $1-\mathrm{mg} / \mathrm{kg}$ group, $82 \%$ and $80 \%$ of the chicks became immobile following the first $15-\mathrm{sec}$ induction period, while only $40 \%$ and $30 \%$ of the birds in the 2 - and $4-\mathrm{mg} / \mathrm{kg}$ groups showed the response initially. Moreover, the overall number of inductions needed to elicit the reaction showed a tendency to increase with increasing levels of tranquilization. Chicks in the 0-, 1-, 2-, and $4-\mathrm{mg} / \mathrm{kg}$ groups required an average of $1.18,1.30,1.90$, and 1.70 inductions before showing the immobility reaction. A one-way analysis of variance run on the number of inductions needed to elicit immobility revealed that the susceptibility differences to immobility were statistically significant $\quad(F=2.93, \quad d f=3 / 37$, $\mathrm{p}<.05$ ).

In the present study, durability of immobility as well as susceptibility to immobility appeared to vary inversely as, a function of level of tranquilization. Moreover, those birds receiving high doses of Pacitran showed little if any evidence of emotionality prior to or following the test of immobility, while control birds exhibited the usual escape and distress behaviors associated with being handled. Thus, these data augment those of previous investigators in showing that manipulations designed to either increase or decrease fear exert a reliable influence on the immobility reaction in domestic chickens.

\section{REFERENCES}

BELLOFF G B \& HSU, B Su-9064, a water soluble tranquilizer for handling broilers and replacement pullets. Avian Diseases, 1963, 7, 50-55.

CHAMPION, L. R., ZINDEL, H. C., RINGER, R. K., \& WOLFORD, J. H. The performance of started pullets treated with Su-9064 (Pacitran) prior to transport. Poultry Science, 1966, 45, $1359-1368$.

GALLUP, G. G., JR., CREEKMORE, H, S., $\&$ HILL, W. E., III. Shockenhanced immobility reactions in chickens: Support for the fear hypothesis. Psychological Record, 1970, 20, 243-245.

GALLUP, G. G., JR., \& NASH, R. F. "Animal hypnosis": A fear reaction in domestic chick ens. Paper presented at the meeting of the Psychonomic Society, San Antonio, November 1970.

GALLUP, G, G., JR., NASH, R. F., POTTER, R. J., \& DONEGAN, N. H. Effect of varying conditions of fear on immobility reactions in domestic chickens (Gallus gallus). Journal of Comparative \& Physiological Psychology, $1970,73,442-445$.

GARREN, H. W., \& HILL, C. H. The effects of continuously feeding tranquilizing agents to young White Leghorns. Poultry Science, 1957, 36, 1386-1387.

GILMAN, T. T.. MARCUSE, F. L., \& MOORE, A. U. Animal hypnosis: A study of the induction of tonic immobility in animals. Journal of Comparative \& Physiological Psychology, 1950, 43, 99-111.

RATNER, S. C. Comparative aspects of hypnosis. In J. Gordon (Ed.), Handbook of clinical and experimental hypnosis. New York: Macmillan, 1967. Pp. 550-587.

RATNER, S. C., \& THOMPSON, R. W. Immobility reactions (fear) of domestic fowl as a function of age and prior experiences. Animal Behaviour, 1960, 8, 186-191.

NOTE

1. A research report providing a detailed description of the tranquilizing drug and procedures for using it can be obtained from The Gland-O-Lac Co., 1818 Leavenworth Street, Omaha, Nebr. 68101 . 